\title{
Effects of limited irrigation water volumes on near-isohydric 'Montepulciano' vines trained to overhead trellis system
}

\author{
Oriana Silvestroni ${ }^{1} \cdot$ Alberto Palliotti $^{2} \cdot$ Bruno Di Lena $^{3} \cdot$ Vitale Nuzzo $^{4} \cdot$ Paolo Sabbatini $^{5} \cdot$ Tania Lattanzi $^{1}$. \\ Vania Lanari ${ }^{1}$ (1)
}

Received: 19 February 2020 / Revised: 20 May 2020 / Accepted: 28 August 2020 / Published online: 7 September 2020

(c) The Author(s) 2020

\begin{abstract}
The thermal increase, due to the changed climatic context, is leading to marked variations in the yield and quality of the grapes and causing an increase in the use of water resources in several viticultural areas. Nevertheless, in some environments, rainfalls are scarce and there is no water availability. In this study, we compared the impact of low water irrigation volumes (DI, replacement of $70 \%$ of crop evapotranspiration) with respect to non-irrigated vines (NI), on the physiological, yield and qualitative performances of near-isohydric variety 'Montepulciano', trained to overhead trellis system, which requires a high-water supply. The stomatal conductance and photosynthesis values, in basal and median leaves, were higher in DI vines. All NI leaves suffered water stress, showing in the youngest leaves (position 20 and 25 along the main shoot) higher carbon isotope discrimination $\left(\delta^{13} \mathrm{C}\right)(-25.38 \%$ and $25-25.77 \%$, respectively). At harvest, DI vines showed yield higher of $30 \%$ and $33 \%$ than NI vines in 2005 and 2006, respectively, and 18\% in 2007. In environments with prolonged water shortage and low water resource, near-isohydric 'Montepulciano' vines, trained to overhead trellis system and irrigated with limited volumes, determined a significant improvement of 'vineyard efficiency' with a yield of $19.2 \mathrm{t} / \mathrm{ha}$ with respect to $13.4 \mathrm{t} / \mathrm{ha}$ of NI vines, ensuring also more sugar content (+31\%), anthocyanin concentration $(+13 \%)$ and polyphenolic substances $(+8 \%)$ than NI vines.
\end{abstract}

Keywords Deficit irrigation · Grape composition · Leaf water potential · Photosynthesis · Vineyard efficiency

Communicated by L. Bavaresco.

Electronic supplementary material The online version of this article (https://doi.org/10.1007/s11738-020-03132-x) contains supplementary material, which is available to authorized users.

Vania Lanari

v.lanari@staff.univpm.it

Oriana Silvestroni

o.silvestroni@univpm.it

Alberto Palliotti

alberto.palliotti@unipg.it

Bruno Di Lena

bruno.dilena@regione.abruzzo.it

Vitale Nuzzo

nuzzo.vitale@unibas.it

Paolo Sabbatini

sabbatin@msu.edu

\section{Introduction}

Water stress is the most important factor limiting grapevine growth in the Mediterranean area. Timing, intensity and duration of water stress coupled with excessive irradiance and temperature determine the impact of drought on grapevine (Chaves et al. 2010). In addition, climate change is

1 Dipartimento di Scienze Agrarie, Alimentari e Ambientali, Università Politecnica delle Marche, Ancona, Italy

2 Dipartimento di Scienze Agrarie Alimentari e Ambientali, Università di Perugia, Perugia, Italy

3 Centro Agrometeorologico Regionale Scerni, Chieti, Italy

4 Dipartimento delle Culture Europee e del Mediterraneo: Architettura, Ambiente, Patrimoni Culturali, Università degli Studi della Basilicata, Matera, Italy

5 Department of Horticulture, Michigan State University, East Lansing, MI, USA 
increasing global temperatures and reducing rainfall events, leading to a dramatic decrease in water availability for agriculture and exposing viticulture to greater risks due to the possible change of terroir elements as well as yields and grape quality (IPCC 2014). Thermal increase would, therefore, promote the expansion of wine-growing areas and the quality of wines in northern Europe, endangering, on the contrary the Mediterranean areas where new strategies to adapt to climate change need to be implemented (Palliotti et al. 2017; Silvestroni et al. 2016, 2018).

A recent study on the analysis of the thermal increase and its impact in some viticultural areas of the Abruzzo region, through the relationship with bioclimatic indices, showed that the temperatures during the months March to June, corresponding to vegetative growth, influence the harvest date in Montepulciano vines (Di Lena et al. 2019). The summer temperatures, from July to September, corresponding to the ripening period, affect, instead, the grape sugar concentration (Lanari et al. 2014).

In grapevines cultivated on hillsides south exposed, long periods of summer drought and excessive radiation occur during the growing season, also associated with water scarcity, leading to a strong vapor pressure deficit between leaf and atmosphere. These phenomena may be increased by the overhead trellis, such as 'Tendone', like the 'Pergola' training system, widespread in southern Italy and used for table grapes also in Chile, Australia, Argentina and other countries (Freeman et al. 1992). The 'Tendone', in its classical form, is a horizontal canopy with four canes orthogonally tied on a single wire system lie on a poles system at about $1.8 \mathrm{~m}$ above the ground level. Shoots are freely standing on the same wire system forming a complete overhead canopy, allowing the passage of mechanical equipment's under the canopies, shading the soil during the growing season. In this training system, grapevine canopies are able to intercept high solar radiation levels coupled with high leaf area index (Nuzzo et al. 2005; Giorio and Nuzzo 2012). Therefore, the 'Tendone' trellis system is also characterized by higher water demand, when compared to vertical shoot positioning systems (Nuzzo et al. 2005).

It is well known that under soil water deficit one of the primary physiological responses of $\mathrm{cv}$. Montepulciano is a partial or total stomata closure, allowing leaf to maintain a favourable leaf turgor but limiting gas exchange, preventing chronic photo-inhibition and avoiding chlorotic and necrotic areas on sun-exposed leaves (Palliotti et al. 2008, 2009, 2014). For these behaviours the cv. Montepulciano was classified as isohydric (Palliotti et al. 2008, 2014) or near-isohydric (Tombesi et al. 2014) and less adapted to face the multiple summer stress conditions than other grapevine varieties (Pallioti et al. 2014). Our working hypothesis is that the near-isohydric behaviours of 'Montepulciano', make this variety particularly useful for evaluating the effects of limited volumes of irrigation water and its response to the climatic variations in progress in this area (Di Lena et al. 2019).

Moreover, in grapevine, C3 species plant, the stomatal conductance ( $\mathrm{gs}$ ) is related to carbon isotope discrimination $\left(\Delta^{13} \mathrm{C}\right)$ via its effect on the $\mathrm{Ci} / \mathrm{Ca}$ ratio (the ratio between intercellular and atmospheric concentration of $\mathrm{CO}_{2}$ ). Carbon isotope discrimination is a measure of the ${ }^{13} \mathrm{C} /{ }^{12} \mathrm{C}$ ratio in plant tissues compared to the air ratio, as described by the equation $\Delta=a+(b-a) \times(\mathrm{Ci} / \mathrm{Ca})$ (Farquhar et al. 1989). Here ' $a$ ' assumes the theoretical value of $4.4 \% o$ and is the discrimination during the diffusion of carbon dioxide from the atmosphere to the chloroplasts through the stomatic pores, and hence, it is against the slower moving $\mathrm{CO}_{2}$ containing carbon- $13\left({ }^{13} \mathrm{C}\right)$. And ' $b$ ' assumes the value of $27 \%$ and represents the discrimination by the Rubisco enzyme when $\mathrm{CO}_{2}$ reacts with RuBP. Furthermore, the analysis of the ${ }^{13} \mathrm{C}$ discrimination is a valid method of estimating intrinsic water-use efficiency (WUEi, the ratio between Pn and gs), that can be used to study the plant-environment interactions and identify genotypes tolerant or resistant to water shortage (Farquhar et al. 1989).

For example, Gaudillère et al. (2002) used carbon isotope composition of berry sugar as a proxy of vine water status in field conditions. More recently, Bchir et al. (2016) used the carbon isotope discrimination as an indicator of vine water status and WUE.

Stomatal and non-stomatal factors interact to limit downregulation of photosynthesis during the hottest hours of the day and to avoid deterioration of fruit chemical composition (Medrano et al. 2002). However, when water stress is limited to short periods could exerts positive effects on grape quality with increases in anthocyanins (Chaves et al. 2007) and tannins concentration (Herrera et al. 2015). Contrarily, longer periods of stress induce drastic reductions in shoots and berries growth with negative impact on yield and grape quality at harvest, leaf photoinhibition and consequent permanent photo-damages (Palliotti et al. 2008, 2009). A severe water deficit after veraison can lead to high basal leaf senescence (Silvestroni et al. 2005; Palliotti et al. 2008), opening fruiting zone and increasing light penetration at the level of the cluster and inducing changes in berry composition (Santos et al. 2005).

There are numerous studies carried out in areas where natural water availability is limited but is present as the irrigation resource as in Argentina and California. There are also many environments where rain events and irrigation water are scarce, as in central-northern Italy, where the irrigation technique is not widespread, is an additional cost and the water resource is limited. Therefore, the aim of our study was to evaluate the benefits that can be obtained from vines using moderate irrigation volumes and the combination with the overhead 'Tendone' training system, which combines 
diffused light conditions on the clusters and high thermal and luminous resources, which, however, require a highwater supply. The study aimed to achieve a dual objective based on water savings, even in areas where dry summers are increasingly occurring, and on the preservation of the yields and quality of the grapes in overhead trellis 'Montepulciano' grapevines, near-isohydric variety, investigating on the effects of canopy development and physiology, yield and grape quality.

\section{Materials and methods}

\section{Plant material, experimental conditions and experimental design.}

The trial was carried out over three years $(2005,2006$ and 2007) in a hillside non-irrigated vineyard within the D.O.C. 'Montepulciano d'Abruzzo' area located in Orsogna (Abruzzi region, Central Italy lat. $42^{\circ} 13^{\prime} \mathrm{N}$, long. $14^{\circ} 16^{\prime} \mathrm{E}$ ). The cv 'Montepulciano' is one of the main Italian grapevine varieties, cultivated on about 27.000 ha (ISTAT 2010), mainly distributed in the central and southern Italy.

The vineyard was planted on a clay-loamy soil, in a slight slope (4\%) and south exposed. Mature grapevines (10 years old) of Vitis vinifera L. cv 'Montepulciano' (clone R7) grafted on 1103 Paulsen rootstock were trained to overhead 'Tendone' trellis system, the most important viticultural combination (cultivar and training system) in south-central Italy. Trellis system consisted of a $1.80 \mathrm{~m}$ about high stake for each vine. Two orthogonal cane wires were cantilevered at the top of the stake and a grid of shoot support wires spaced $0.50 \mathrm{~m}$ apart. Vines had a 1.2-1.4 $\mathrm{m}$ high trunk, with four arms and a cane per arm orthogonally displayed on the cane wires. Canes were about 8 buds pruned during the winter period. The standard summer pruning operations, consisting in the removal of unproductive shoots and basal lateral shoots, was made before flowering. At pea-size, when necessary, leaves near the clusters were removed and clusters were arranged up-down below the canopy. Recommended crop protection practices were carried out according to local practices determined by field scouting, experience and weather conditions. Weeds growth was mechanically controlled by repeated shallow tillage, carried out orthogonally in both directions of the rows. As ordinary, soil was kept bare with three to four tillage interventions were made from berry set until the harvest.

Vines were planted in square distribution at $2.50 \mathrm{~m}$ (1.600 vines/ha). In this experiment, rainfed vines (NI) were compared with irrigated vines using limited water irrigation volumes (DI). The experimental design consisted of two main blocks of $2000 \mathrm{~m}^{2}$ ( $0.2 \mathrm{ha}$ ), each with about 320 vines. Each block was divided into two plots of about 160 vines.
In each block one plot was equipped with irrigation systems consisting of pressure compensating emitters with an $8 \mathrm{~L} / \mathrm{h}$ discharge rate. In July, during the first stage of fruit growth until veraison, water was applied to DI vines according with the following equation:

Applied Water $(\mathrm{AW})=(0.7 \times(K c \times E T o)-$ Rainfall $)$.

ETo was estimated by the Penman-Monteith equation (Allen et al. 1998); meteorological variables used in the equation and rainfall were measured by a standard automatic weather station, located near the vineyard, of the Regional meteorological Centre (ARSSA, Regional Agency for Agricultural Development Services). A single mid-season Kc value of 0.7 was used to calculate ETc from the daily value of ETo (Doorenbos and Pruitt 1977). The ETc was further reduced by a coefficient of 0.7 in order to apply the deficit irrigated (DI) treatment. This threshold was chosen taking into account the paper of Messaoudi and El-Fellah (2004), and Grimes and Williams (1990) has showed that yield was maintained until a relative ETc reduction of 0.6-0.8.

The soil of the site was a typical loamy-clay soil, with about $3 \%$ of gravel, highly calcareous ( $>30 \%$ of total $\left.\mathrm{CaCO}_{3}\right)$ and of low fertility ( $0.48 \%$ organic matter). The soil had a depth of about $1.5 \mathrm{~m}$, a bulk density $1.43 \mathrm{~g} / \mathrm{cm}^{-3}$, with field capacity of $31.8 \%$, permanent wilting point of $18.6 \%$ and available water of $189 \mathrm{~mm} / \mathrm{m}^{-1}$. The net depth irrigation dose was calculated considering a maximum permissible depletion fraction of 0.6 along the first $0.6 \mathrm{~m}$ of soil profile and irrigation application efficiency of 0.9 (Phocaides 2007). Water balance calculation started from the second half of June and finished at veraison.

During 2005 and 2007, irrigation effects on yield and grape quality were evaluated, while in 2006, data collection was expanded to include the measure of physiological and morphological vine parameters to better characterize the impact of irrigation strategies on near-isohydric 'Montepulciano' vines.

\section{Vine water status, gas exchange and chlorophyll fluorescence}

On 3rd August 2006, after the four DI interventions, physiological data were taken on five vines per plot monitoring median midday leaf water potential $(\Psi 1)$ using a pressure chamber (PMS Instrument Co., Corvallis, OR, USA, model 600 ), in order to evaluate the vines water status. The leaf petioles were cut within 1-2 s and placed in the pressure chamber within 10-15 s. Measurements were taken from 1200 to $1330 \mathrm{~h}$ on 5 mature and well-exposed leaves, sampled from the central part of the primary shoot of vines chosen per treatment in each plot (for a total of 10 leaves per treatment, 5 in each plot and 20 per block). 
In the same day, 5 median and basal leaves per plot (for a total of 40 leaves) from the main shoots were chosen to measure gas exchange and chlorophyll fluorescence.

Leaves were measured under saturating light [photosynthetically active radiation (PAR) $>1200 \mu$ mol photons/ $\left(\mathrm{m}^{2} \mathrm{~s}\right)$ ], in the morning (0930-1130), using a portable, opensystem LCA3 infrared gas analyser (ADC BioScientific, Hoddesdon, England). The system had a broad leaf chamber with a $6.25 \mathrm{~cm}^{2}$ window, and the measurement of net photosynthesis (Pn) and stomatal conductance (gs) was made at ambient relative humidity with airflow adjusted to $350 \mathrm{~mL} /$ min. Using the same system, but covering leaves with a dark cloth, was measured the leaf dark respiration (Rd).

In each treatment and in each plot, 5 leaves (for a total of 20 leaves, 10 per treatment) were chosen to measure the chlorophyll fluorescence parameters (maximum quantum yield of photosystem II), using a portable pulse modulation FMS1 fluorometer (Hansatech Instruments Ltd., King's Lynn, Norfolk, England). The FMS1 was equipped with a halogen white lamp source to generate a supersaturating light pulse of $17.000 \mu \mathrm{mol} \mathrm{m} \mathrm{m}^{-2} \mathrm{~s}^{-1}$ applied for $0.7 \mathrm{~s}$ for fluorescence induction and delivered to the leaf sample through an optical fibre probe inserted at $45^{\circ}$ inclination into a closed black dome fitted over the leaf-clip. After $30 \mathrm{~min}$ of dark adaptation, for each leaf was calculated automatically the maximum quantum yield of photosystem II (PSII) determined as Fv/Fm ratio, which indicates impairment of PSII activity. Fv is the variable fluorescence obtained by the difference between Fm and Fo. Fm is the maximal fluorescence yield in the dark and Fo is the basal fluorescence produce in dark-adapted leaves. The FMS1 also provides the measure of the parameter 'Area' (Am), which is proportional to the size of the pool of electron acceptor in the PSII (plastoquinones). Then as swift as is the time, which Fm is reached, minor is Am, and the electron acceptor amount involved in the process is lower.

\section{Vegetative growth}

At harvest in the 2006 season (14 October 2006), length of shoots and number of leaves were measured on 5 vines per treatment. Just after, 3 shoots per vine were sampled, stored in suitable protective bags, and quickly brought to the laboratory to measure main and lateral stem lengths, and onesided surface area of all leaves on each stem by means of a Li-3100 photometric area-integrating meter (LiCor, Lincoln, NE, USA). Fresh weight of the stems was also measured. The internodes length was calculated as a ratio between shoots length and leaves number.

Moreover, from the same 3 shoots, leaves growth on nodes 5, 10, 15, 20 and 25, and lateral leaves developed from node $15 \pm 1$, were separately sampled and leaf area and fresh weight measured. After, leaves were placed in a ventilated oven at $70{ }^{\circ} \mathrm{C}$ to constant weight, the specific leaf weight was calculated as the ratio between dry weight and leaf area.

\section{Carbon isotope discrimination measurements}

In the 2006 season, the same leaves (from the 5th to 25 th node position, each 5 nodes of the main shoots and leaves from the 15th node position of the lateral shoots) used to determine the leaf area and specific weight were used for the measurement of the carbon isotope discrimination $\left(\delta^{13} \mathrm{C}\right)$. $24 \mathrm{~h}$ before sampling, all leaves in the 15 th node position of the main and lateral shoots were artificially shaded using an aluminium foil, to depress leaf photosynthesis, i.e., nonstructural carbohydrates formation (to reduce sugar and starch formation), thus leaving only constitutional carbohydrates. Leaves at the 15 th node on the primary shoot were sampled also after direct exposition to solar radiation.

Once the specific weight was determined, the dried leaves were ground with grinder into a fine homogeneous powder and $0.20-0.30 \mathrm{mg}$ subsamples were used for the $\delta^{13} \mathrm{C}$ analy-

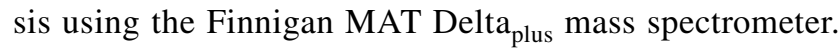
Carbon isotope composition was expressed as the isotopic abundance of stable isotopes of carbon, as ${ }^{13} \mathrm{C} /{ }^{12} \mathrm{C}$ ratio, of the sample compared to that of international standard Pee Dee Belemnite (Farqhuar et al. 1989).

\section{Vine yield and grape composition}

The vineyard was inside the 'Montepulciano d'Abruzzo' DOP area, which require a minimum alcohol content of wines of $11.5-12 \%$. Then, clusters were harvested when the average soluble solids of the vineyards were higher of $20^{\circ}$ Brix.

From 30 vines per treatment, randomly chosen in each plot, grapes were individually picked and the total number of clusters per vine was counted and weighed. Mean individual cluster weight was calculated as the ratio of total cluster weight per vine (yield) to the total number of clusters per vine.

About $3 \mathrm{~kg}$ of berries per treatment from harvested clusters was sampled and split into three sub-samples of about one kg each. From each sub-sample, 100 berries were sampled, weighted to determine average berry fresh weight. Then, the berries were crushed to obtain juice to measure total soluble solids (TSS), $\mathrm{pH}$ and titratable acidity (TA). Total soluble solids were measured with a temperaturecompensating Maselli LR-01 digital refractometer (Maselli Misure, Parma, Italy); $\mathrm{pH}$ with a Crison $\mathrm{pH}$ meter (Crison Instruments, Barcelona, Spain) by a glass electrode and TA with a Crison Titrator (Crison Instruments) using $0.25 \mathrm{~N}$ $\mathrm{NaOH}$ to a pH 7.00 endpoint, expressed as $\mathrm{g} / \mathrm{L}$ of tartaric acid equivalent. 
Each year, the concentration of anthocyanin and polyphenol was determined according to Mattivi (2004) using the same berry analysed for must composition. Berries were further pressed to obtain a dried sample (skins and seeds only), which were placed in a jar containing an extractive buffer solution of hydrochloric acid $(15 \mathrm{~mL}$ in $1 \mathrm{~L}$ of water), homogenized with an Ultra-Turrax T25 (Janke and Kunkel, IKA-Werke, Staufen, Germany) for $1 \mathrm{~min}$ at 10,000 rpm, and a subsample of homogenate was, subsequently, transferred to a centrifuge tube and centrifuged (model ALC 4218, International, Cologno Monzese, Milano, Italy) for $10 \mathrm{~min}$ at $3257 \mathrm{~g}$. Liquid phases were collected in dark glass bottles $(25 \mathrm{~mL})$ and used for anthocyanin determination. Initially, the liquid phase was diluted with ethanol hydrochloric acid and analysed in a $10 \mathrm{~mm}$ cuvette on a spectrophotometer (UV-1601, Shimadzu Corporation, Kyoto, Japan) at $520 \mathrm{~nm}$. Anthocyanin concentration was calculated as malvidin 3 -glucoside chloride equivalents ( $\mathrm{mg} / \mathrm{kg}$ of grape).

To determine the concentration of phenolic substances, the liquid phase was diluted with water. Then, $1 \mathrm{~mL}$ portion was transferred into a $20 \mathrm{~mL}$ calibrated flask, and $2 \mathrm{~mL}$ of methanol, $5 \mathrm{~mL}$ of water and $1 \mathrm{~mL}$ of Folin-Ciocalteu reagent were added. After $3 \mathrm{~min}, 4 \mathrm{~mL}$ of sodium carbonate $(10 \%)$ was added and the solution was left to stand for $90 \mathrm{~min}$. Absorbance was then registered at $700 \mathrm{~nm}$ on the spectrophotometer using a $10 \mathrm{~mm}$ cuvette. The concentration was determined using a calibration curve and expressed as $(+)$-catechin, $\mathrm{mg} / \mathrm{kg}$ of grape.

\section{Statistical analysis}

The results were tested with Statistica version 4.3 (StatSoft, Tulsa, OK, USA) for homogeneity of variance and subjected to ANOVA. The graphical representation was made using Sigma Plot version 10 (SPSS, Chicago, IL, USA). In each year, data of physiological parameters, grape composition at harvest and yield components were tested using means separation calculated by applying the Student-Newman-Keuls test at $P \leq 0.05$. In the figures, leaf area, specific leaf weight and $\delta^{13} \mathrm{C}$ are shown as mean values $\pm \mathrm{SE}$.

\section{Results}

\section{Environmental conditions and irrigation treatments}

Over the three seasons, from budburst (day of the year (DOY) 98, 103 and 87 in 2005, 2006 and 2007, respectively) to harvest (DOY 290, 287 and 277 in 2005, 2006 and 2007, respectively), the heat accumulation, expressed as growing degree days (GDD, base $10^{\circ} \mathrm{C}$ ) ranged from a minimum of 1891 in 2005 to a maximum of 2002 in 2007 (Table 1). Total rainfall from budburst to veraison resulted different from a
Table 1 Growing degree days (GDD, base $10{ }^{\circ} \mathrm{C}$ ), rainfall, crop evapotranspiration (ETc), water supplied to 'Montepulciano' plots according to irrigation treatments and total water amount in each season

\begin{tabular}{llrr}
\hline Parameters & 2005 & 2006 & 2007 \\
\hline GDD from budburst to harvest & 1891 & 1969 & 2002 \\
Rainfall from budburst to veraison (mm) & 237 & 165 & 320 \\
Rainfall from veraison to harvest (mm) & 172 & 185 & 38 \\
Rainfall from budburst to harvest (mm) & 409 & 350 & 358 \\
Estimated ETc from budburst to veraison (mm) & 323 & 346 & 340 \\
Estimated ETc from veraison to harvest (mm) & 191 & 198 & 215 \\
Estimated ETc from budburst to harvest (mm) & 514 & 544 & 555 \\
Irrigation supplied to DI (mm) & 40.0 & 64 & 56 \\
Total water amount DI from budburst to har- & 432 & 363 & 377 \\
vest (rain + irrigation) (mm) & & & \\
\hline
\end{tabular}

Budburst, veraison and harvest occurred, respectively, on 10 April, 31 July and 17 October in 2005; on 13 April, 3 August and 14 October in 2006; and on 26 March, 28 July and 3 October in 2007

minimum of $165 \mathrm{~mm}$ to a maximum of $320 \mathrm{~mm}$, in 2006 and 2007, respectively, while the precipitations from veraison to harvest were very low in 2007 equal to $38 \mathrm{~mm}$ than the 2005 and 2006 seasons ranging from 172 to $185 \mathrm{~mm}$ (Table 1). Total rainfall from budburst to harvest revealed variable precipitation distribution over the three growing seasons, showing differences from April (around DOY 10s0) to the beginning of July (about DOY 182) ranging from a minimum of $102 \mathrm{~mm}$ in 2006 to a maximum of $256 \mathrm{~mm}$ in 2007 (Fig. 1, Supplemental Fig. 1). However, at the end of May 2007, there was a rainfall event of $79.8 \mathrm{~mm}$ in a single day (DOY 147), representing approximately $20 \%$ of the rain falling from March to harvest (Fig. 1, Supplemental Fig. 1). Rainfalls of this magnitude in sloping soil cause substantial losses to runoff and reduce greatly the useful rain for recovering soil water reserves. In the summer period, the 2007 season was characterized by maximum air temperature (Supplemental Fig. 1), associated with high evaporative demand.

Cumulative values of the crop evapotranspiration (ETc) in 2007, from budburst to veraison varied between $323 \mathrm{~mm}$ in 2005 and 346 in 2006, instead from veraison to harvest were between 191 and 215, respectively, in 2005 and 2007 (Table 1). The ETc from budburst to harvest amounted to the highest value of $555 \mathrm{~mm}$ (Table 1), with great daily ETc values maintained over $4 \mathrm{~mm}$ for an extended period in July, from DOY 196 to DOY 211, even reaching peaks of about $5 \mathrm{~mm}$ near veraison (DOY 209) (Fig. 1, Supplemental Fig. 1). The seasons 2005 and 2006 showed weekly ETc summation values similar, between budburst and harvest, respectively, of $514 \mathrm{~mm}$ and $544 \mathrm{~mm}$. However, in 2005, regular precipitation distribution was detected, between the end of June and the beginning of July (from 172 to 185 DOY), no rainfalls occurred for 24 days and the maximum air temperature reached a maximum value not excessively 


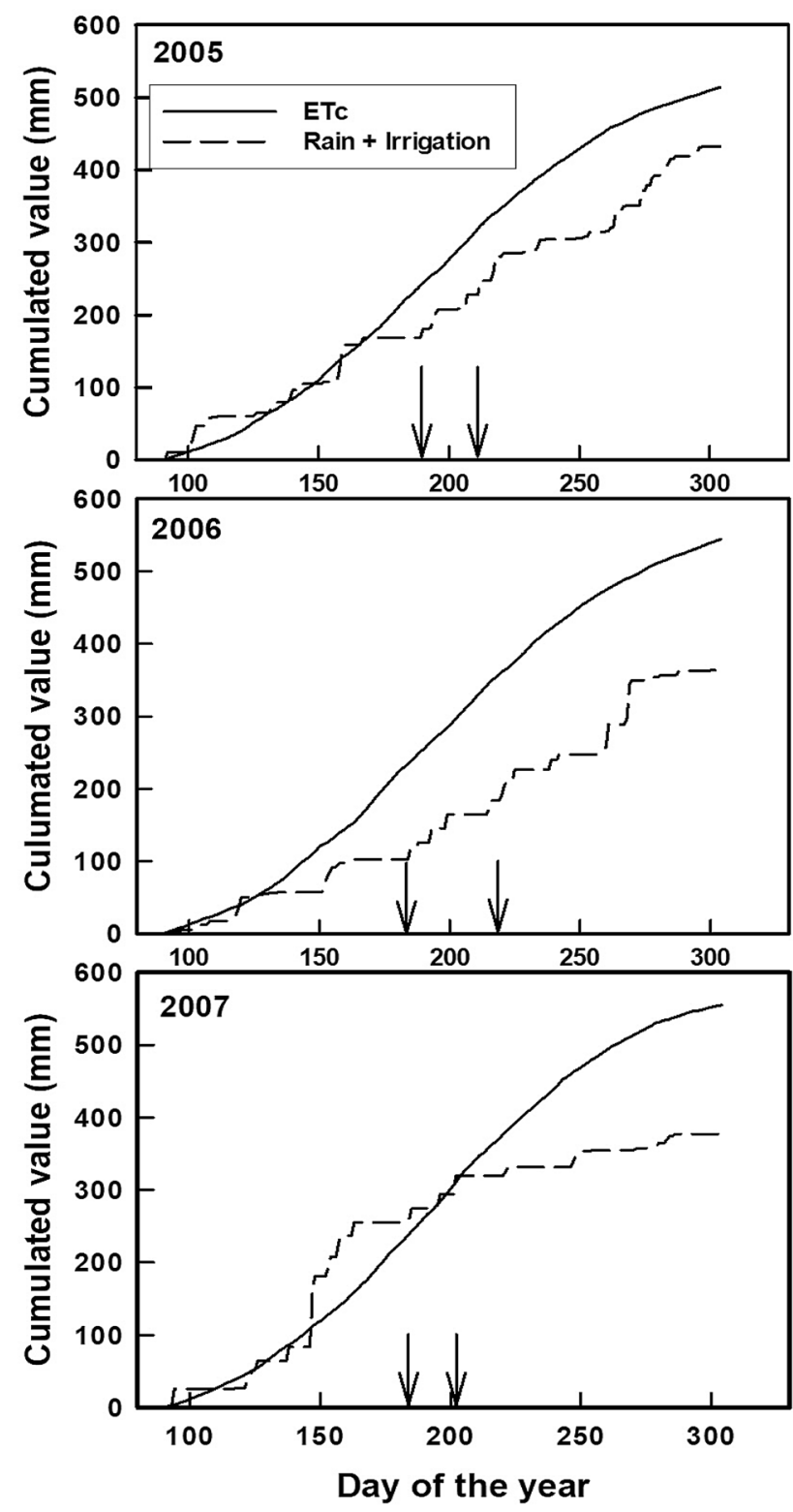

Fig. 1 Cumulative seasonal evolution of crop evapotranspiration (ETc) of 'Montepulciano' vines and water supply (rain + irrigation) in 2005, 2006 and 2007 seasons. The arrows indicate the irrigation season

high $\left(33{ }^{\circ} \mathrm{C}\right)$, daily ETc values topped $4 \mathrm{~mm}$, with a peak of $5 \mathrm{~mm} /$ day (DOY 179). In this condition, an irrigation of $12 \mathrm{~mm}$ was carried out on DOY 190, but after two days, a rainfall event of $39 \mathrm{~mm}$ occurred (Fig. 1, Supplemental Fig. 1). Another two irrigations were scheduled of $19 \mathrm{~mm}$ each on DOY 207 and 213, in which the air temperatures averaged maximum values of $35^{\circ} \mathrm{C}$ and did not occur rainfall (Fig. 1, Supplemental Fig. 1).

Before the veraison phase in the 2006 and 2007 seasons, by the middle of June and all July (from 174 to 212 DOY), the daily ET rates were maintained above 3-4 mm/day with maximum air temperatures of $35{ }^{\circ} \mathrm{C}$ in 2006 and even $40{ }^{\circ} \mathrm{C}$ in 2007. In July, rainfall events were very limited with an insignificant rain of $5.4 \mathrm{~mm}$ in a single day in 2006 and $7.7 \mathrm{~mm}$ in two rains in 2007 (Fig. 1, Supplemental Fig. 1). For this reason, four irrigations of about $16 \mathrm{~mm}$ each were considered necessary on DOY 185, 193, 199 and 214 in 2006 and on DOY 188, 196 and 203 of about $16 \mathrm{~mm}$ each in 2007. The seasonal irrigation volumes were distributed in three interventions in 2005 and 2007 for a total of $40.0 \mathrm{~mm}$ and $56 \mathrm{~mm}$, respectively, and four in 2006 totaling $64 \mathrm{~mm}$. The irrigations were rather low and increased water availability from bud break to harvest of just $9 \%, 18 \%$ and about $15 \%$ of natural rainfall for the three respective years (Table 1).

\section{Effects on leaf water potential, gas exchange and chlorophyll fluorescence}

On August 2006, in the central hours of the day, the leaf water potential $(\Psi \mathrm{l})$ on the median leaves was very low in both treatments (Table 2). NI vines showed values of $-1.88 \mathrm{MPa}$, significantly lower of $45 \%$ than DI ones, evidencing a marked water stress. Consequently, the gs values were rather modest in both treatments, but as expected, significantly higher in DI vines $(+43 \%$ in basal leaf and $+36 \%$ in median ones) compared to NI vines. These last showed a significant reduction in Pn of $30 \%$ in basal and $47 \%$ in median leaves but accompanied by a higher dark respiration (Rd) until to $-2.2 \mu \mathrm{mol} \mathrm{CO} \mathrm{Cm}^{-2} \mathrm{~s}^{-1}$, than DI vines (Table 2). Despite the effects of the drought were particularly pronounced in leaves from NI vines, fluorescence parameters, including the $\mathrm{Fv} / \mathrm{Fm}$ ratio (i.e. the maximum quantum yield of assimilation), showed no significant differences. However, the Am parameter was lower in NI median leaves than DI vines (Table 3).

\section{Effects on vine morphological characteristics and on carbon isotope composition}

The shoot apex of DI vines developed longer $(+26 \%)$ and heavier $(+38 \%)$ shoots, with more leaves $(+20 \%)$, well spaced (internode length $+9 \%$ ), which resulted in a significantly greater area per shoots $(+34 \%)$ compared to NI vines (Table 3). Additionally, vine size, indexed as one-year-old cane pruning weight, resulted higher in DI vines (Table 3 ). In both treatments the leaf area decreased from the basal leaf (the oldest) in fifth position (5th node) to the youngest apical leaf in twenty-fifth position (25th node).

Leaves developed in the position 5, in both treatments, were characterized by a similar leaf area $\left(199 \mathrm{~cm}^{2}\right.$ in NI vines and $197 \mathrm{~cm}^{2}$ in DI vines). The single leaf area determined from leaf position 10 to 25 in DI vines ranged from $190 \mathrm{~cm}^{2}$ to $67 \mathrm{~cm}^{2}$, while in NI vines the leaf area decreased 
Table 2 Leaf water potential $(\Psi 1)$, photosynthesis $(\mathrm{Pn})$, stomatal conductance (gs), dark respiration $(\mathrm{Rd})$ and chlorophyll fluorescence parameters measured in the 2006 season, in median and basal leaves of near-isohydric 'Montepulciano' vines, trained in overhead trellis system, limited irrigated (DI) and rain-fed vines (NI)

\begin{tabular}{|c|c|c|c|c|c|c|}
\hline & \multicolumn{3}{|l|}{ Median } & \multicolumn{3}{|l|}{ Basal } \\
\hline & NI & DI & Sign & NI & DI & Sign \\
\hline$\Psi 1(\mathrm{MPa})$ & $-1.88 b$ & $-1.30 \mathrm{a}$ & $* *$ & & & \\
\hline $\operatorname{gs}\left(\mathrm{mmol} \mathrm{H} \mathrm{H}_{2} \mathrm{~m}^{-2} \mathrm{~s}^{-1}\right)$ & $39 b$ & $68 \mathrm{a}$ & $* *$ & $35 b$ & $55 \mathrm{a}$ & $* *$ \\
\hline $\operatorname{Pn}\left(\mu \mathrm{mol} \mathrm{CO} \mathrm{CO}_{2} \mathrm{~m}^{-2} \mathrm{~s}^{-1}\right)$ & $2.25 b$ & $4.2 \mathrm{a}$ & $* *$ & $1.67 \mathrm{~b}$ & $2.38 \mathrm{a}$ & $* *$ \\
\hline $\operatorname{Rd}\left(\mu \mathrm{mol} \mathrm{CO} \mathrm{CO}^{-2} \mathrm{~s}^{-1}\right)$ & $-2.2 b$ & $-1.7 \mathrm{a}$ & $* *$ & $-2.1 b$ & $-1.4 \mathrm{a}$ & $* *$ \\
\hline Fo & $626 \mathrm{a}$ & $606 \mathrm{a}$ & n.s & $602 \mathrm{a}$ & $623 a$ & n.s \\
\hline $\mathrm{Fm}$ & $2358 \mathrm{a}$ & $2603 a$ & n.s & $2437 \mathrm{a}$ & $2852 \mathrm{a}$ & n.s \\
\hline Fv & $1732 \mathrm{a}$ & $1997 \mathrm{a}$ & n.s & $1835 \mathrm{a}$ & $2228 \mathrm{a}$ & n.s \\
\hline $\mathrm{Fv} / \mathrm{Fm}$ & $0.726 \mathrm{a}$ & $0.763 \mathrm{a}$ & n.s & $0.752 \mathrm{a}$ & $0.779 \mathrm{a}$ & n.s \\
\hline Area & $38,560 \mathrm{~b}$ & $54,280 \mathrm{a}$ & $* *$ & $35,360 \mathrm{a}$ & $35,920 a$ & n.s \\
\hline
\end{tabular}

Measurements done on August 3, 2006 ( $n=10$ leaves per treatment)

**A significant difference between treatments at $P<0.05$ according to within-row mean separation performed with Student-Newman-Keuls test and shown by letters from $167 \mathrm{~cm}^{2}$ until $44 \mathrm{~cm}^{2}$ (Fig. 2a). DI irrigated vines reported a SLW (specific leaf weight, as the ratio of leaf dry weight and leaf area), significantly lower than NI ones (Fig. 2b). The 'Montepulciano' leaves in both DI (50\% of ETo) and NI vines showed a similar pattern of $\delta^{13} \mathrm{C}$ along the shoot. The $\delta^{13} \mathrm{C}$ values of leaves decreased from 5 to 10th node, then increased almost linearly from median to apical leaves at the shoot apex (Fig. 2c). The $\delta^{13} \mathrm{C}$ values, analysed on primary leaves of DI vines, clearly showed the effects of the irrigation treatments, independently of the node position; leaves of DI vines were characterized by lowest $\delta^{13} \mathrm{C}$ values, ranging from $-26.65 \%$ to $-25.77 \%$, from basal (5th node) to apical leaf (25th node). In NI treatment, considering the same leaf position, $\delta^{13} \mathrm{C}$ values oscillated from $-26.26 \%$ o to $-24.53 \%$, indicating a substantial enrichment of ${ }^{13} \mathrm{C}$. The $\delta^{13} \mathrm{C}$ analysis showed a more pronounced water stress on NI apical leaves, which reached $-25.38 \%$ and $-25.77 \%$, respectively, in the positions 20 and 25 .

In both treatments, leaves exposed to direct sunlight and shaded leaves were characterized by the highest SLW values, ranging from 7.7 and $8.6 \mathrm{mg} / \mathrm{cm}^{2}$, then shaded lateral leaves, resulting about 20\% heavier (Fig. 3a). Regardless the treatment, leaves taken from 15 th node position and exposed to direct sunlight showed a lower $\delta^{13} \mathrm{C}$, than those artificially shaded, but the highest $\delta^{13} \mathrm{C}$ was occurred in shaded lateral leaves (Fig. 3b).

\section{Effects on yield and grape composition and vineyard efficiency}

Vines were harvested on 17, 14 and 3 October in 2005, 2006 and 2007, respectively.

The DI treatment, over the three years, led to significant improvement in grapevine yield, 30\% higher in 2005 $(+3.6 \mathrm{~kg})$ and $2006(+2.6 \mathrm{~kg})$, while in 2007 the increase was just of $18 \%(+1.3 \mathrm{~kg})$. In NI vines a significant reduction in the cluster weight of $13 \%$ in 2005, 36\% in 2006 and $16 \%$ in 2007 was found, associated with a decrease in the berry size (-26\% in 2006 and $-15 \%$ in 2007). The number of clusters per vine was higher in 2007 season when compared to the first 2 years, and different between treatments only in the first year of the trial $(+7$ cluster in DI vines), despite the cluster weight resulted in a rise of yield, while berry number remained unaffected by the treatment over the three seasons (Table 4).

Moreover, DI treatments did not influence berry composition at harvest and no statistical differences were found in TSS, pH and TA (Table 5). In 2005, the low TSS coupled with the high content of TA (6.9-7.6 g/L), suggested a delay of the berry ripening process (Supplemental Table 1). In 2006 and 2007, NI vines resulted in higher anthocyanins and total polyphenol concentrations than DI vines, respectively, of $22 \%$ and $26 \%$ in the 2006 season and $23 \%$ and only $6 \%$ in the 2007 (Table 5).

Considering the vineyard efficiency of the combination 'Montepulciano-Tendone', in the three years of the trial, limited water volumes have ensured a substantial increase in yield and in the sugar concentration with a maximum difference of $1304 \mathrm{~kg} / \mathrm{ha}$ in 2005. In 2006 and 2007, DI vines showed higher phenolic potential, an important component that defines the macrostructure of the resulting wines, with maximum differences in anthocyanins of about $3.2 \mathrm{~kg} / \mathrm{ha}$ in the 2006 season and total polyphenols of about $5.5 \mathrm{~kg} / \mathrm{ha}$ in 2007 (Supplemental Table 1).

\section{Discussion}

In rain-fed condition, the water limitation, from fruit set to veraison, when the shoot elongation is rapid, reduces grapevine growth, reducing vine leaf area and inducing adaptive responses to optimize the use of assimilates (Palliotti et al. 


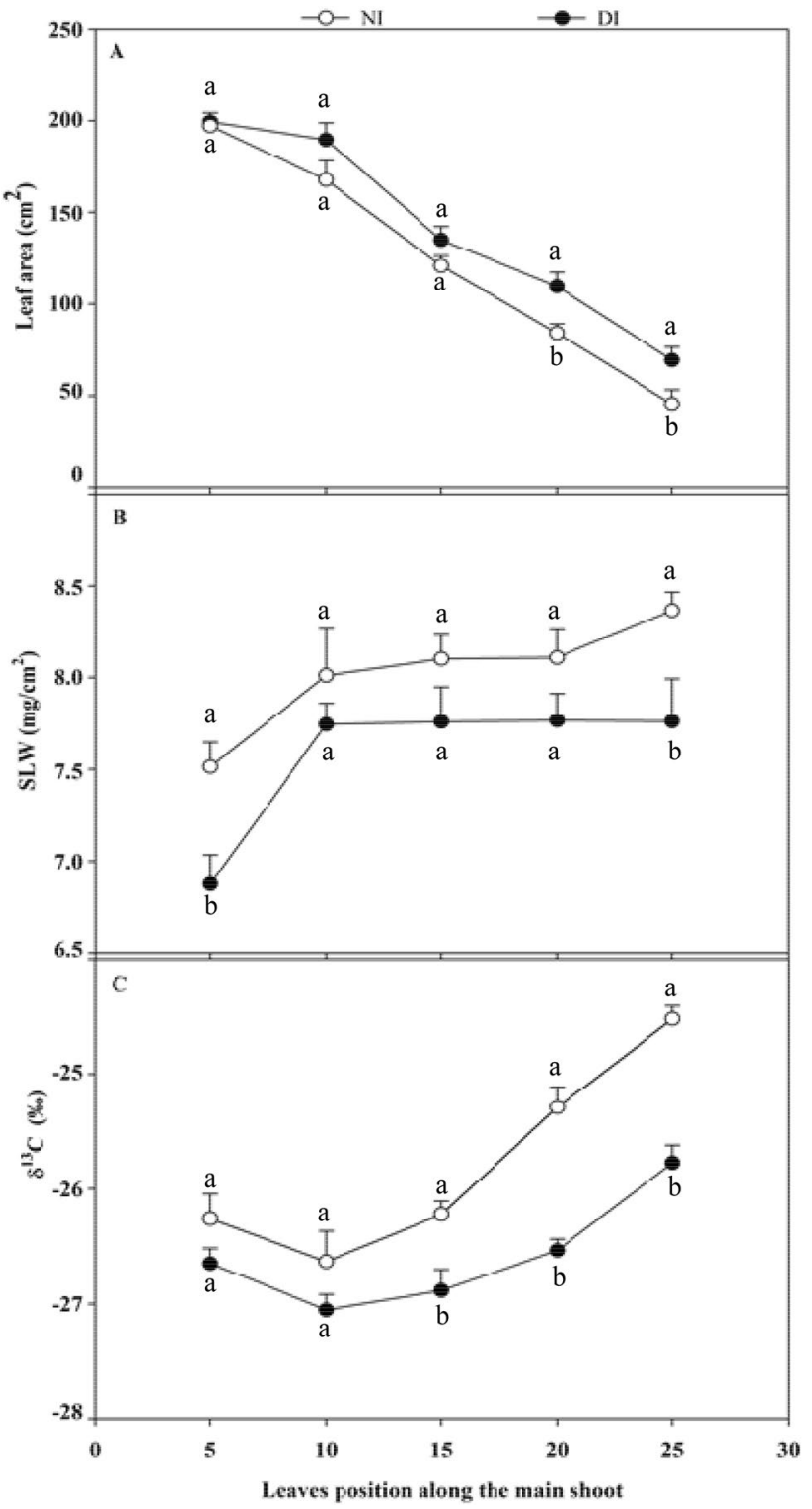

Fig. 2 a Leaf area, b specific leaf weight (SLW) and (c) carbon isotope composition $\left(\delta^{13} \mathrm{C}\right)$ in the 2006 season of 'Montepulciano' vines, trained in overhead trellis system, subjected to limited irrigated (DI) and rain-fed vines (NI). Leaf position was counted from the apex (position 5) of the shoot (mean SE, $n=10$ leaves per treatment)
2014). Leaf expansion rate and the internode length are the most sensitive processes to water deficit, observed both in field (Schultz and Matthews 1993; Gomèz del Campo et al. 2003) and in pot (Lanari et al. 2015, 2018).

The DI vine biometry closely related to water availability suggests that irrigated vines have used a greater amount of dry matter for the growth of leaf blades and internodes, and the lower SLW indicates that the low volumes of irrigation water may have a positive effect on shoot growth, as a result of higher assimilation rate. Instead, the similar SLW of shaded lateral leaves in both treatments shows that the DI treatment did not create internal canopy shading conditions where lateral leaves are characterized by low specific weight. The limitations to vine growth imposed by water limitation were mainly due to low capability of leaves to maintain positive daily balance between carbon assimilation and respiration (Chaves and Olivera 2004; Escalona et al. 2012).

In NI vines, Rd (dark respiration) resulted higher than that in DI vines and, as expected, Pn was reduced. The role played by the gs on leaf ability to coordinate $\mathrm{CO}_{2}$ exchanges under stress, with values lower than $50 \mathrm{mmol} / \mathrm{m}^{2} \mathrm{~s}^{-1}$, which suggests dominant non-stomatal limitations (severe water stress) (Cifre et al. 2005). On the contrary, gs values of DI vines highlighted stomatal limitations, because of a moderate water stress. Despite statistical differences in chlorophyll fluorescence parameters were not found between treatments, in the median leaves of NI vines the Am parameter was lower than DI vines, suggesting a net decrease in the pool of plastoquinones on the reductant site of photosystem II and then a stress index (Palliotti et al. 2015).

In our trial the primary leaves of DI vines clearly showed the effects of the irrigation treatment, since they were characterized by the lowest $\delta^{13} \mathrm{C}$ (Farquhar et al. 1982) and the greatest discriminatory capacity against atmospheric ${ }^{13} \mathrm{CO}_{2}$ $\left(\Delta^{13} \mathrm{C}\right)$. On the contrary, all leaves of NI 'Montepulciano' grapevines suffered water stress and showed higher $\delta^{13} \mathrm{C}$ values indicating lower $\Delta^{13} \mathrm{C}$, as reported in other similar studies in field (Chaves et al. 2007; Lanari et al. 2014) and in pot (Lanari et al. 2015, 2018). Based on the inverse relationship between $\Delta^{13} \mathrm{C}$ and water-use efficiency (WUE), the $\Delta^{13} \mathrm{C}$ analysis is a valid method of estimating WUE. In our study $\Delta^{13} \mathrm{C}$ suggests low WUE in DI, highlighting a higher gas exchange rate. In both treatments, the high quantity of ${ }^{13} \mathrm{C}$ on
Table 3 Vegetative and pruning parameters recorded at harvest 2006 of 'Montepulciano' vines, trained in overhead trellis system, limited irrigated (DI) and rain-fed vines (NI)

\begin{tabular}{llllll}
\hline & Shoot length $(\mathrm{m})$ & $\begin{array}{l}\text { Leaves }(n / \\
\text { shoot })\end{array}$ & $\begin{array}{l}\text { Leaf area/Shoot } \\
\left(\mathrm{cm}^{2} / \mathrm{shoot}\right)\end{array}$ & $\begin{array}{l}\text { Internodes' } \\
\text { length }(\mathrm{cm})\end{array}$ & Cane weight $(\mathrm{g})$ \\
\hline NI & $1.07 \mathrm{~b}$ & $20 \mathrm{~b}$ & $3623 \mathrm{~b}$ & $5.3 \mathrm{~b}$ & $44 \mathrm{~b}$ \\
DI & $1.45 \mathrm{a}$ & $25 \mathrm{a}$ & $5487 \mathrm{a}$ & $5.8 \mathrm{a}$ & $71 \mathrm{a}$ \\
Sign & $* *$ & $* *$ & $* *$ & $* *$ & $* *$ \\
\hline
\end{tabular}

Measurements done at harvest $2006(n=15$ shoots per treatment)

**A significant difference between treatments at $P<0.05$ according to within-column mean separation performed with Student-Newman-Keuls test and shown by letters 


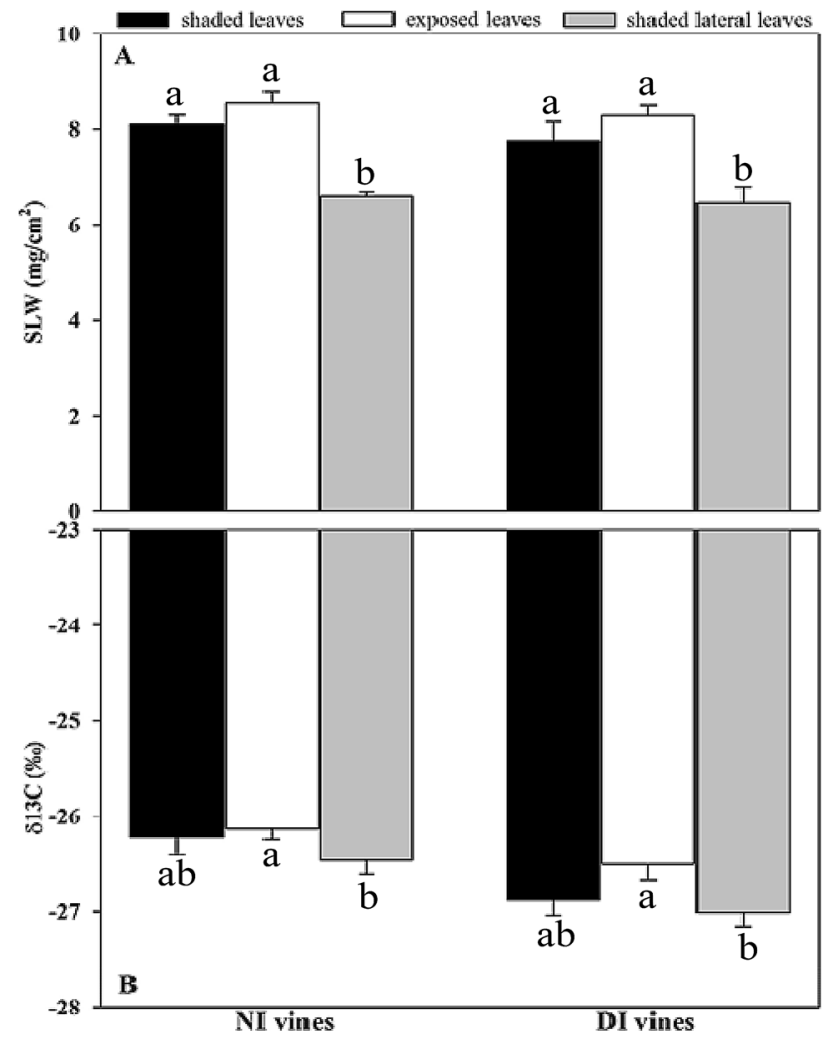

Fig. 3 a Specific leaf weight (SLW) and (b) carbon isotope composition $\left(\delta^{13} \mathrm{C}\right)$ measured in the 2006 season on shaded and exposed primary leaves and shaded lateral leaves of 'Montepulciano' vines, trained in overhead trellis system, subjected to limited irrigated (DI) and rain-fed vines (NI). Leaves were sampled in position 15 of the main shoot (mean SE, $n=10$ leaves per treatment)

youngest leaves in apical position (20th and 25th node) suggests a reduction in $\mathrm{gs}$, and consequently a reduction in $\mathrm{Ci}$, generating a physiological condition for low discrimination against atmospheric ${ }^{13} \mathrm{CO}_{2}$ (Farquhar et al. 1982).

Between budburst and bloom, stored carbohydrates from the previous growing season support shoot growth and nutrients (Yang and Hori 1979); therefore, the development of basal leaves was sustained by the remobilization of stored carbohydrates in the reserve organs. The highest $\Delta^{13} \mathrm{C}$ on basal leaves can, thus, be related to environmental stresses during the previous year, being $\delta^{13} \mathrm{C}$ signal in these leaves mainly referred to their constitutional ${ }^{13} \mathrm{C}$ coming from the reserve organs of the plant (Brugnoli and Farquhar 2000; Souza et al. 2005), but also related partly to assimilated ${ }^{13} \mathrm{C}$ during the current year.

The $\delta^{13} \mathrm{C}$ measured in apical tissue leaves represents part of the carbon likely assimilated by older leaves and subsequently moved to younger leaves. Shaded lateral leaves tissue reported the lowest ${ }^{13} \mathrm{C}$ concentration, mainly in DI vines, suggesting the highest $\mathrm{Pn}$ and gs that contributed to the highest discrimination in lateral leaves (Souza et al. 2005). Lateral leaves were developed after primary leaves and, being artificially shaded, were poor in recently formed sugar and starch; therefore, the $\Delta^{13} \mathrm{C}$ referred to constitutional carbon reflected long-term fluctuations in the water availability and light interception. In leaves exposed to direct sunlight, the $\Delta{ }^{13} \mathrm{C}$ referred to the accumulation of constitutional carbon in carbohydrates produced, stored and subsequently moved, and of assimilated carbon in the photosynthetic process to more rapid turn-over (soluble sugars and starch) that reflected the environmental conditions of the moment.

The values of carbon isotope discrimination obtained on 'Montepulciano' leaves showed a different trend along the main shoot, with respect to those observed in similar study on 'Sangiovese' vines (Lanari et al. 2014), confirming the different physiological behaviours of the two genotypes (Palliotti et al. 2008; Tombesi et al. 2014). 'Montepulciano' vines show the high capacity of leaves to adapt to water limitation through quick stomata closure (isohydric behaviour), leading a low discrimination of atmospheric ${ }^{13} \mathrm{CO}_{2}$ and an increase of the WUE.

The yield obtained from NI vines resulted lower than DI ones over the three years, due to the decrease of cluster and berry weight. In 2006 and 2007 the level of irrigation applied did not modify cluster number per vine and berry number per cluster, as reported in literature (Lanari et al. 2014). Probably, during the three experimental years characterized by drought summer periods, the water supplied in July, when the bud differentiation (which determine the cluster number per shoot)
Table 4 Yield parameters at harvest in 'Montepulciano' vines, trained in overhead trellis system, limited irrigated (DI) and rain-fed vines $(\mathrm{NI})$

\begin{tabular}{|c|c|c|c|c|c|c|c|c|c|}
\hline & \multicolumn{3}{|l|}{2005} & \multicolumn{3}{|l|}{2006} & \multicolumn{3}{|l|}{2007} \\
\hline & NI & DI & Sign & NI & DI & Sign & NI & DI & Sign \\
\hline Yield (kg/vine) & $8.4 \mathrm{~b}$ & $12.0 \mathrm{a}$ & $* *$ & $5.2 b$ & $7.8 \mathrm{a}$ & $* *$ & $6.1 b$ & $7.4 \mathrm{a}$ & $* *$ \\
\hline Cluster weight (g) & $311 \mathrm{~b}$ & $356 a$ & $* *$ & $138 b$ & $218 \mathrm{a}$ & $* *$ & $138 \mathrm{~b}$ & $164 \mathrm{a}$ & $* *$ \\
\hline Berry weight (g) & $2.77 \mathrm{a}$ & $2.84 \mathrm{a}$ & n.s & $1.62 \mathrm{~b}$ & $2.20 \mathrm{a}$ & $* *$ & $1.41 \mathrm{~b}$ & $1.65 \mathrm{a}$ & $* *$ \\
\hline Cluster (N/vine) & $27 b$ & $34 \mathrm{a}$ & $* *$ & $38 \mathrm{a}$ & $36 \mathrm{a}$ & n.s & $45 \mathrm{a}$ & $46 \mathrm{a}$ & n.s \\
\hline Berry (N/cluster) & $112 \mathrm{a}$ & $125 \mathrm{a}$ & n.s & $85 a$ & $99 \mathrm{a}$ & n.s & $98 \mathrm{a}$ & $99 a$ & n.s \\
\hline
\end{tabular}

**A significant difference between treatments at $P<0.05$ according to within-row within-season mean separation performed with Student-Newman-Keuls test and shown by letters 
Table 5 Must composition at harvest in 'Montepulciano' vines, trained in overhead trellis system, limited irrigated (DI) and rain-fed vines $(\mathrm{NI})$

\begin{tabular}{|c|c|c|c|c|c|c|c|c|c|}
\hline & \multicolumn{3}{|l|}{2005} & \multicolumn{3}{|l|}{2006} & \multicolumn{3}{|l|}{2007} \\
\hline & NI & DI & Sign & NI & DI & Sign & NI & DI & Sign \\
\hline Soluble Solids $\left({ }^{\circ}\right.$ Brix $)$ & $21.3 \mathrm{a}$ & $21.7 \mathrm{a}$ & n.s & $23.0 \mathrm{a}$ & $22.6 \mathrm{a}$ & n.s & $22.1 \mathrm{a}$ & $22.0 \mathrm{a}$ & n.s \\
\hline $\mathrm{pH}$ & $3.08 \mathrm{a}$ & $3.19 \mathrm{a}$ & n.s & $3.38 \mathrm{a}$ & $3.42 \mathrm{a}$ & n.s & $3.38 \mathrm{a}$ & $3.24 \mathrm{a}$ & n.s \\
\hline Titratable acidity (g/L) & $7.6 \mathrm{a}$ & $6.9 \mathrm{a}$ & n.s & $6.2 \mathrm{a}$ & $5.9 \mathrm{a}$ & n.s & $6.2 \mathrm{a}$ & $6.8 \mathrm{a}$ & n.s \\
\hline Anthocyanins (mg/kg) & $2013 a$ & $1612 b$ & $* *$ & $2152 \mathrm{a}$ & $1689 b$ & $* *$ & $2112 \mathrm{a}$ & $1625 b$ & $* *$ \\
\hline Poliphenols (mg/kg) & $3585 a$ & $2734 b$ & ** & $3876 \mathrm{a}$ & $2847 b$ & $* *$ & $3888 \mathrm{a}$ & $3669 b$ & ** \\
\hline
\end{tabular}

**A significant difference between treatments at $P<0.05$ according to within-row within-season mean separation performed with Student-Newman-Keuls test and shown by letter and fruit set (which defines the berry number per cluster) occurred, not impacted on those processes. Previous studies (Roby et al. 2004; Matthews and Nuzzo 2007) reported that the berry size is most influenced by water stress between fruit set and veraison, which coincides with the phase of pericarp cell division, than other yield components (such as berry number per cluster and the cluster number per vine) due to double effect exerted on their constitution (relative skin, pulp and seeds weight) and their chemical composition.

The grape composition did not show statistical differences in the sugar concentration, $\mathrm{pH}$ and titratable acidity, probably; regardless the irrigation treatment, the vines reached a good balance between total leaf area and yield that allowed a regular cluster ripening.

The higher concentration of anthocyanin and total polyphenols in NI vines (rain-fed vines) can be explained by higher temperature on clusters that were exposed to direct sunlight, as a result of vine growth inhibition by water stress that caused a reduction of leaf area and then a more open canopy, suggesting a positive metabolic response of vines to both light and temperature (Santos et al. 2007). Moreover, the lower concentration of anthocyanin and polyphenols in DI vines may be related to a significantly higher berry size that may reduce the skin to pulp ratio of the berry (Roby and Matthews 2004; Roby et al. 2004).

The impact of the cont rolled deficit irrigation on 'Montepulciano' trained to 'Tendone' trellis system, in a viticultural area characterized by prolonged water scarcity, determined a significant improvement in vineyard efficiency (as capacity of the vineyard to ensure the highest quantity of components that define the macrostructure of obtainable wines), guaranteeing in every years higher phenolic potential (including the anthocyanin matrix) and sugar concentration than the non-irrigated vines.

\section{Conclusions}

In rain-fed vineyards located in the hillside in central southern Italy, 'Montepulciano' vines trained to 'Tendone' system showed a good yield and grape quality only when the rains are well distributed during the spring and summer period, which has happened in 2005 (Fig. 1, Supplemental Table 1, Fig. 1). But, when rainfall is erratic or scarce, yield of cv. 'Montepulciano' drops to a quite low amount. These traits may be related to the near-isohydric behaviour of cv 'Montepulciano', that responds to drought stress conditions with a suddenly stomata closure, which determine lasting and intense declines of net photosynthesis, followed by drastic reductions in the vineyard efficiency.

Our data revealed that low volumes of irrigation water in the most dry and hot period of the year improve gas exchange rate, which increases yield without significant effects on sugar accumulation and acidity degradation, even if anthocyanins and polyphenols concentrations are lower than rain-fed vines.

Author contribution statement SO, PA, Di LB and NV had the idea, set the trial in vineyard and proceeded to carry out the sampling. SO and NV contributed by making their equipment available for some analyses. SO, NV and PA developed the initial manuscript and added details and examples. LV contributed with the writing of this manuscript, data processing and creation of figures and tables. LT carried out laboratory analysis, insertion and data processing. SP provided language corrections and critical reading of the manuscript. We confirm that, all above-listed co-authors contributed equally to this work. 
Acknowledgements This research was in partial fulfillment of requirements for the Doctoral Degree of Dr. Vania Lanari. The authors thank the Patricelli wine-growing farm that hosted the trial (Orsogna, Abruzzi region, Central Italy).

Funding Open access funding provided by Università Politecnica delle Marche within the CRUI-CARE Agreement.

Open Access This article is licensed under a Creative Commons Attribution 4.0 International License, which permits use, sharing, adaptation, distribution and reproduction in any medium or format, as long as you give appropriate credit to the original author(s) and the source, provide a link to the Creative Commons licence, and indicate if changes were made. The images or other third party material in this article are included in the article's Creative Commons licence, unless indicated otherwise in a credit line to the material. If material is not included in the article's Creative Commons licence and your intended use is not permitted by statutory regulation or exceeds the permitted use, you will need to obtain permission directly from the copyright holder. To view a copy of this licence, visit http://creativecommons.org/licenses/by/4.0/.

\section{References}

Allen RG, Pereira LS, Raes D, Smith M (1998) Crop evapotranspiration-guidelines for computing crop water requirements. In: FAO Irrigation and drainage. Food and Agriculture Organization, Rome, p. 56

Bchir A, Escalona JM, Galléc A, Hernández-Montes E, Tortosa I, Brahama M, Medrano H (2016) Carbon isotope discrimination $\left(\delta^{13} \mathrm{C}\right)$ as an indicator of vine water status and water use efficiency (WUE): looking for the most representative sample and sampling time. Agric Water Manag 167:11-20

Brugnoli E, Farquhar GD (2000) Photosynthetic fractionation of carbon isotopes. In: Leegood RC, Sharkey TD, Von Caemmerer S (eds) Photosynthesis: physiology and metabolism: advances in photosynthesis and respiration. Kluwer Academic Publishers, The Netherlands, pp 399-434

Chaves MM, Oliveira MM (2004) Mechanisms underlying plant resilience to water deficits: prospects for water-saving agriculture. J Exp Bot 55:2365-2384

Chaves MM, Santos TP, Souza CR, Ortuǹo MF, Rodrigues ML, Lopes CM, Maroco JP, Pereira JS (2007) Deficit irrigation in grapevine improves water-use efficiency while controlling vigour and production quality. Ann Appl Biol 150:237-252

Chaves MM, Zarrouk O, Francisco R, Costa JM, Santos T, Regalado AP, Rodrigues ML, Lopes CM (2010) Grapevine under deficit irrigation: hints from physiological and molecular data. Ann Bot 105:661-676

Cifre J, Bota J, Escalona JM, Medrano H, Flexas J (2005) Physiological tools for irrigation scheduling in grapevine (Vitis vinifera L.). An open gate to improve water-use efficiency? Agric Ecosys Environ 106:159-170

Doorenbos J, Pruitt WO (1977). Crop water requirements. FAO Irrigation and Drainage Paper No. 24. FAO, Rome

Escalona JM, Tomás M, Martorell S, Medrano H, Ribas-Carbó M, Flexas J (2012) Carbon balance in grapevines under different soil water supply: importance of whole plant respiration. Aust J Grape Wine Res 18:308-318

Farqhuar GD, Ehleringer JR, Hubick KT (1989) Carbon isotope discrimination and photosynthesis. Ann Rev Plant Physiol Plant Mol Biol 40:503-537
Farquhar GD, O'Loreal MH, Berry JA (1982) On the relationship between carbon isotope discrimination and the intercellular carbon dioxide concentration in leaves. Aus J Plant Physiol 9:121-137

Freeman BM, Tassie E, Rebbechi MD (1992) Training and Trellising. In: Coombe BG, Dry PR (eds) Practices. Viticulture, vol. 2, Adelaide, Winetitles, Australia

Gaudillère JP, VanLeeuwen C, Ollat N (2002) Carbon isotope composition of sugars in grapevine, an integrated indicator of vineyard water status. J Exp Bot 53:757-763

Giorio P, Nuzzo V (2012) Leaf area, light environment, and gas exchange in 'Montepulciano' grapevines trained to 'Tendone' trellising system. Plant Biosyst 146(2):322-333

Grimes DW, Williams LE (1990) Irrigation effects on plant water relations and productivity of Thompson seedless grapevines. Crop Sci 30:255-260

Gómez del Campo M, Ruiz C, Baeza P, Lissarrague JR (2003) Drought adaptation strategies of four grapevine cultivars (Vitis vinifera L.): modification of the properties of the leaf area. J Int Sci Vigne Vin 37:131-143

Herrera JC, Bucchetti B, Sabbatini P, Comuzzo P, Zulini L, Vecchione A, Peterlunger E, Castellarin SD (2015) Effect of water deficit and severe shoot trimming on the composition of Vitis vinifera L. Merlot grapes and wines. Aus J Grape Wine Res 21:254-265

IPCC (2014) Summary for policymakers. In: Field CB, Barros VR, Dokken DJ, Mach KJ, Mastrandrea MD et al. Climate Change 2014: impacts, adaptation, and vulnerability. Part A: global and sectoral aspects. Contribution of working group II to the Fifth Assessment Report of the Intergovernmental Panel on Climate Change. Cambridge University Press, Cambridge, United Kingdom and New York pp. 1-32

ISTAT (2010) https://dati-censimentoagricoltura.istat.it. Accessed 20 Nov 2019

Lanari V, Palliotti A, Sabbatini P, Howell GS, Silvestroni O (2014) Optimizing deficit irrigation strategies to manage vine performance and fruit composition of field-grown 'Sangiovese' (Vitis vinifera L.) grapevines. Sci Hortic 179:239-247

Lanari V, Silvestroni O, Palliotti A, Green A, Sabbatini P (2015) Plant and leaf physiological responses to water stress in potted 'Vignoles' grapevine. HortScience 50(10):1492-1497

Lanari V, Silvestroni O, Palliotti A, Sabbatini P (2018) Plant and leaf responses to cycles of water stress and re-watering of 'Sangiovese' grapevine. Folia Horticult 30(1):27-38

Di Lena B, Silvestroni O, Lanari V, Palliotti A (2019) Climate change effects on cv. Montepulciano in some wine-growing areas of the Abruzzi region (Italy). Theor Appl Climatol 136(3):1145-1155

Matthews MA, Nuzzo V (2007) Berry size and yield paradigms on grapes and wines quality. Acta Hortic 754:423-436

Mattivi F (2004) Metodo rapido per la stima degli antociani e dei polifenoli totali nelle uve. Metodo interno, Istituto Agrario San Michele all'Adige

Medrano H, Escalona JM, Bota J, Gulías J, Flexas J (2002) Regulation of photosynthesis of $\mathrm{C} 3$ plants in response to progressive drought: stomatal conductance as a reference parameter. Ann Bot 89:895-905

Messaoudi Z, El-Fellah A (2004) Optimisation de l'irrigation de la vigne dans le plateau de Meknès (Maroc). Cah Options Méditer 62:197-201

Nuzzo V, Palese AM, Lazzari L, Giorio P (2005) Vegetative and reproductive growth potential of 'Montepulciano' grapevines trained to the 'Tendone' trellis system. Acta Hort 689:209-216

Palliotti A, Frioni T, Tombesi S, Sabbatini P, Cruz-Castillo JG, Lanari V, Silvestroni O, Gatti M, Poni S (2017) Double pruning grapevines as a management tool to delay berry ripening and control yield. Am J Enol Vitic 68:412-421 
Palliotti A, Silvestroni O, Petoumenou D (2009) Photosynthetic and photoinhibition behavior of two field-grown grapevine cultivars under multiple summer stresses. Am J Enol Vitic 60:189-198

Palliotti A, Silvestroni O, Petoumenou D, Vignaroli S, Berrios JG (2008) Evaluation of low-energy demand adaptive mechanisms in Sangiovese grapevine during drought. J Int Sci Vigne Vin 42:41-47

Palliotti A, Tombesi S, Frioni T, Silvestroni O, Lanari V, D’Onofrio C, Matarese F, Bellincontro A, Poni S (2015) Physiological parameters and protective energy dissipation mechanisms expressed in the leaves of two Vitis vinifera L. genotype under multiple summer stresses. J Plant Physiol 185:84-92

Palliotti A, Tombesi S, Silvestroni O, Lanari V, Gatti M, Poni S (2014) Changes in vineyard establishment and canopy management urged by earlier climate-related grape ripening: a review. Sci Hortic 178:43-54

Phocaides A (2007) Handobook on pressurized irrigation techniques. FAO, Rome

Roby G, Matthews MA (2004) Relative proportions of seed, skin and flesh, in ripe berries from Cabernet Sauvignon grapevines grown in a vineyard either well irrigated or under water deficit. Austr J Grape Wine Res 10:74-82

Roby G, Harbertson JF, Adams DA, Matthews MA (2004) Berry size and vine water deficits as factors in winegrape composition: anthocyanins and tannins. Aust J Grape Wine Res 10:100-107

Santos TP, Lopes CM, Rodrigues ML, Souza CR, Maroco JP, Pereira JS, Ricardo-da-Silva JM, Chaves MM (2007) Partial rootzone drying irrigation affects cluster micro-climate improving fruit composition of 'Moscatel' field-grown grapevines. Sci Hortic 112:321-330

Santos TP, Lopes CM, Rodrigues ML, Souza CR, Ricardo-Da-Silva JM, Maroco JP, Pereira JS, Chaves MM (2005) Effects of partial root-zone drying irrigation on cluster microclimate and fruit composition of field-grown Castelão grapevine. Vitis 44:117-125
Schultz HR, Matthews MA (1993) Xylem development and hydraulic conductance in sun and shade shoots of grapevine (Vitis vinifera L.): evidence that low light uncouples water transport capacity from leaf area. Planta 190(3):393-406

Silvestroni O, Lanari V, Lattanzi T, Palliotti A (2018) Delaying winter pruning, after pre-pruning, alters budburst, leaf area, photosynthesis, yield and berry composition in Sangiovese (Vitis vinifera L.). Aust J Grape Wine Res 24(4):478-486

Silvestroni O, Lanari V, Lattanzi T, Palliotti A, Sabbatini P (2016) Impact of crop control strategies on performance of high yielding Sangiovese grapevines. Am J Enol Vitic 67:407-418

Silvestroni O, Mattioli S, Neri D, Palliotti A, Carthechini A (2005) Down-regulation of photosynthetic activity for field-grown grapevines. Acta Hort 689:285-291

Souza CR, Maroco JP, Santos TP, Rodrigues ML, Lopes CM, Pereira JS, Chaves MM (2005) Impact of deficit irrigation on water use efficiency and carbon isotope composition $(\delta 13 \mathrm{C})$ of fieldgrown grapevines under Mediterranean climate. J Exp Bot 402(56):2163-2172

Tombesi S, Nardini A, Farinelli D, Palliotti A (2014) Relationship between stomatal behaviour xylem vulnerability to cavitation and leaf water relations in two cultivars of Vitis vinifera. Physiol Plant 152(3):453-464

Yang YS, Hori Y (1979) Studies on retranslocation of accumulated assimilates in 'Delaware' grapevines. I. Retranslocation of $14 \mathrm{C}$-assimilates in the following spring after $14 \mathrm{C}$ feeding in summer and autumn. Tohoku J Agricult Res 30:43-56

Publisher's Note Springer Nature remains neutral with regard to jurisdictional claims in published maps and institutional affiliations. 